\title{
Medicina legal, criminologia e punição: aspectos da trajetória intelectual e profissional de Flamínio Fávero (1895-1982)
}

\author{
Forensic medicine, criminology and punishment: some aspects of \\ intellectual and professional trajectory of Flamínio Fávero (1895-1982)
}

\author{
Marcos César Alvarez¹, Fernando Salla², Kelly Ludkiewicz Alves ${ }^{3}$
}

\begin{abstract}
Alvarez MC, Salla F, Alves KL. Medicina legal, criminologia e punição: aspectos da trajetória intelectual e profissional de Flamínio Fávero (1895-1982). Saúde, Ética \& Justiça. 2012;17(2):57-65.

RESUMO: O artigo discute aspectos da trajetória intelectual e profissional do médico Flamínio Fávero (18951982). Formado pela Faculdade de Medicina de São Paulo, Fávero teve importante atuação no campo da Medicina Legal e das discussões criminológicas no período, bem como atuou no sistema penitenciário do estado. O estudo dessa e de outras trajetórias abre possibilidade de compreensão do papel das elites e de suas representações no que diz respeito ao controle do crime e às práticas e instituições de punição na história da sociedade brasileira.
\end{abstract}

DESCRITORES: Medicina legal/história; Criminologia/história; Médicos/história; Médicos legistas/história; Crime; Punição.

\footnotetext{
Doutor em Sociologia pela Universidade de São Paulo; Professor do Departamento de Sociologia da FFLCH-USP; pesquisador do Núcleo de Estudos da Violência.

2. Doutor em Sociologia pela Universidade de São Paulo; pesquisador do Núcleo de Estudos da Violência.

3. Bacharel em História pela Universidade de São Paulo, mestre em Educação e Ciências Sociais e doutoranda do programa "Educação: História, Política e Sociedade" da Pontifícia Universidade Católica de São Paulo.

Endereço para correspondência: Fernando Salla. Faculdade de Filosofia, Letras e Ciências Humanas, Departamento de Sociologia, Av. Prof. Luciano Gualberto 315, Cidade Universitária, São Paulo, SP. CEP: 05508-900. E-mail: mcalvarez@usp.br.
} 
Alvarez MC et al. Medicina legal, criminologia e punição: aspectos da trajetória intelectual e profissional.

\section{INTRODUÇÃO}

\begin{abstract}
Integralmente dedicado à pesquisa científica e ao magistério, sem o pretender, em virtude de sua modéstia, apresenta-se como modêlo de verdadeiro educador. Não apenas transmite conhecimentos, mas oferece aos seus discípulos o estímulo que resulta de seu exemplo e ressalta da autoridade moral inconteste que emoldura a sua palavra. Os inúmeros trabalhos científicos que publicou atestam os seus elevados e superiores dotes de inteligência e cultura e Ihe grangearam o renome internacional, que hoje usufrui'.
\end{abstract}

O projeto de pesquisa desenvolvido pelo Núcleo de Estudos da Violência da Universidade de São Paulo e intitulado Construção das Políticas de Segurança Pública e o Sentido da Punição, São Paulo (1822-2000), realizado com apoio da Fundação de Amparo à Pesquisa do Estado de São Paulo (FAPESP), buscou levantar fontes e produzir análises referentes ao funcionamento da justiça criminal, das instituições prisionais e de segurança e controle social, bem como dos saberes e das trajetórias intelectuais relacionadas a esses campos num período envolvendo praticamente dois séculos da história institucional do estado. A partir de tal escopo temporal, buscouse estabelecer continuidades e descontinuidades capazes de elucidar as atuais práticas no campo da justiça criminal e da segurança pública que por vezes ainda desafiam a plena vigência do Estado de Direito no país.

No presente artigo, como um dos produtos de tal pesquisa(1), é discutida a trajetória de Flamínio Fávero (1895-1982), médico formado pela Faculdade de Medicina de São Paulo, cuja trajetória intelectual e profissional atravessou os campos da Medicina Legal, da Criminologia e do sistema penitenciário da época. O estudo dessa e de outras trajetórias abre interessantes possibilidade de compreensão do papel das elites e de suas representações nos vários campos de atuação que, na época, se entrecruzavam para equacionar as questões referentes ao crime e à punição em nossa sociedade.

\section{A trajetória intelectual e profissional de Flamínio Fávero}

Professor catedrático de Medicina Legal da Faculdade de Medicina de São Paulo, desde 1923,
Flamínio Fávero destacou-se, entre seus pares, como figura de grande importância, tanto no âmbito do ensino quanto da pesquisa médica em sua época. $\mathrm{Na}$ verdade, em sua trajetória profissional, Fávero obteve projeção igualmente ao atuar em diversas instituições ligadas ao que atualmente poderia ser caracterizado como o campo da segurança pública no Estado de São Paulo. Diante disso, o presente texto procura abordar alguns aspectos da trajetória profissional de Fávero, mais precisamente sua atuação no interior de instituições ligadas aos problemas do crime e da punição, bem como em campos de saber como os da Criminologia e sua interface com a Medicina Legal.

Antes de iniciar a discussão proposta, no entanto, e buscando evitar os anacronismos comuns nas discussões do gênero, faz-se necessário pensar o espaço peculiar que a Medicina Legal ocupava, ou ao menos pretendia ocupar entre os demais saberes e práticas do período. Segundo alguns autores que se debruçaram sobre o tema, houve, a partir da década de 1920, uma intensa atuação de médicos e outros profissionais ligados à área na tentativa de consolidar a Medicina Legal como uma espécie de ciência da moral, capaz de produzir conhecimento acerca dos mais variados âmbitos da vida social, como por exemplo, a delinqüência, a punição, a sexualidade, o trabalho, entre outros, em um processo que se convencionou chamar de "medicalização" da sociedade ${ }^{4}$

$O$ presente artigo, tendo em vista essas amplas ambições da Medicina Legal na época, busca privilegiar as discussões desenvolvidas nesse campo no que diz respeito às questões do crime e da punição. A figura de Fávero é emblemática nesse sentido, uma vez que ele foi de suma importância na busca da consolidação da Medicina Legal como uma disciplina voltada para o estudo dos desvios e da delinqüência, reivindicando para ela não apenas o papel de auxiliar dos agentes de justiça, mas sim de guia e formuladora de políticas na área.

Em um texto intitulado "Evolução scientifica da Medicina Legal no Brasil's, proferido em 1922, Fávero descreve o que, segundo ele, seria a trajetória de formação da Medicina Legal no Brasil. O esquema proposto pelo médico divide sua história em três fases: a primeira, que ele chama de "período estrangeiro", é marcada pela quase inexistência de uma produção científica genuinamente brasileira. Segundo ele, os trabalhos realizados caracterizavam-se pela cópia de

(1) Para alguns outros resultados da citada pesquisa, consultar Alvarez et al. ${ }^{23}$. 
modelos estrangeiros, uma vez que:

Pode-se considerar que o período que vae de 1832 (data da instituição do ensino official da medicina legal no Brasil) até Souza Lima (1877) pouco pesou na evolução scientifica da Medicina Legal, pois, salvas rarissimas excepções, os trabalhos publicados eram, em geral, sem valor, reproduzindo estudos estrangeiros, mormente francezes ${ }^{5}$.

Após esta fase inicial, tem-se o período que ele classifica como o do "início da nacionalização", marcado pela entrada do médico Souza Lima na Faculdade de Medicina do Rio de Janeiro, o qual inaugurou o ensino prático da Medicina Legal, sem contar os inúmeros trabalhos por ele publicados em revistas científicas. Diante disso a atuação de Lima, segundo Fávero "era o estímulo, era o incitamento, era o exemplo aos médicos e aos juristas brasileiros para se interessarem pelas questões medicolegaes nossas e para cuidarem da produção de trabalhos scientificos sobre as nossas leis"5. De qualquer forma, essa fase é caracterizada como um período de transição em que a produção científica se reduzia em sua maioria à interpretação médicolegal de leis brasileiras, porém, tendo como alicerce trabalhos estrangeiros.

O processo de nacionalização, que Fávero caracterizava como a terceira fase, inicia-se a partir da atuação do médico Nina Rodrigues, professor de Medicina Legal da Faculdade de Medicina da Bahia, que:

(...) comprehendeu cedo a necessidade de fazer em nosso proprio paiz a colheita dos elementos de laboratório e de clinica, para solução dos problemas medico-legaes e de criminologia brasileiros, desde que as condições do meio physico, psychologico e social evidentemente não eram em tudo iguaes àquellas que se encontravam na Europa ${ }^{5}$.

De fato, a partir da atuação de Nina Rodrigues, um projeto mais definido de atuação da Medicina Legal emerge no Brasil, em que os profissionais que se pretendiam ligados a esse campo se voltam não apenas para os problemas do crime mas também para problemáticas como a do menor abandonado, do trabalho e das mulheres, entre outras, consolidando paulatinamente uma rede de relações que, na década de vinte, busca institucionalizar-se em torno de associações, publicações e congressos ligados ao tema, sendo justamente Flamínio Fávero, juntamente com figuras como Afrânio Peixoto, Oscar Freire, Leonídio
Ribeiro, um dos "herdeiros" desta tradição. Segundo a antropóloga Mariza Correa, que se debruçou de forma pioneira sobre o tema:

A atuação inicial de Nina Rodrigues, insistindo na criação de um nicho profissional e lutando para mantê-lo, seria acompanhada de uma extensão do campo da Medicina Legal à medida que áreas cada vez mais amplas da vida social eram incorporadas a ela como objetos de interesse do perito. De uma proposta no interior da faculdade à tentativa de aprovação de uma nova lei estadual; da colocação insistente da questão para seus alunos à fundação de uma associação e de uma revista especializadas; do exame dos casos mais diferentes de atentado à ordem social, a sugestões de sua definição e classificação pelos códigos civil e penal, Nina Rodrigues ampliou o circulo do debate sobre o papel da Medicina Legal e a importância do perito ${ }^{6}$.

Pode-se considerar, deste modo, que a esquematização da disciplina feita por Fávero evidencia, primeiramente, a intenção do médico em vincular seu nome à tradição de Nina Rodrigues, bem como tratar a consolidação da Medicina Legal por um viés evolutivo, do qual ele e seus companheiros fariam parte e a quem cabia, naquele momento, sua condução, estimulando-os a ampliar estudos tendo como base as especificidades nacionais, contribuindo assim, para uma maior delimitação do campo de atuação da emergente disciplina, marcado muito mais pela tradição dos nomes do que por uma linha doutrinária clara.

Ainda assim, o debate doutrinário não é totalmente irrelevante ao longo da institucionalização desses e de outros saberes médicos e criminológicos no Brasil da época. A análise da recepção das ideias da assim chamada Escola Positiva - ou mesmo do debate criminológico em geral - no Brasil entre o final do século XIX e início do XX, por exemplo, ajuda a compreender os discursos disponíveis, naquele momento, para os médicos e juristas locais interessados em novas abordagens referentes ao crime e à punição.

\section{Fávero e a escola positiva}

Em fins do século XIX, chegaram ao país ideias que propunham a patologização do ato anti-social, as quais estavam reunidas em torno da assim chamada Escola Positiva, cujo nome de maior expressão era 0 de Cesare Lombroso (1835 a 1909), médico italiano que procurou pensar o crime a partir de bases biológicas(2). Tais ideais sofreram, ao longo do tempo, algumas 
transformações, sendo que o próprio Lombroso abandonou a ênfase estrita que era dada as determinações físicas que motivariam o crime, voltando-se também para a análise dos desvios psicológicos ou mesmo sociais que levariam ao delito. Porém, independentemente das mudanças ocorridas no decorrer de sua trajetória intelectual, suas concepções acerca da punição e da prevenção do crime continuaram seguindo um forte sentido de patologização do crime. Para os defensores do assim chamado biodeterminismo, a pena possuía uma conotação de tratamento e cura, perdendo seu caráter estritamente punitivo e a prevenção, por sua vez, consistia em uma das principais propostas da Escola, uma vez que, se era possível identificar no indivíduo a predisposição ao delito, por que não fazê-lo antes mesmo da prática do crime?

Porém, para se determinar quem eram os indivíduos desviados e que tipo de patologia possuíam, fazia-se necessário a consolidação de um campo científico onde os médicos ganhavam papel de destaque. Somente seu saber poderia analisar, averiguar e medir o delinquente, fixando assim a pena mais adequada para sua moléstia e recuperação.

Vale lembrar que não é objetivo deste texto pensar o espaço e alcance que tais propostas tiveram no que se refere às políticas efetivas de prevenção e de punição adotadas pelo aparato do Estado mas sim averiguar a atuação de Flamínio Fávero tendo em vista as ideias da Escola Positiva, ao refletir até que ponto sua produção e atuação dentro de instituições de controle social contribuíram para a circulação e implementação de tais ideias.

\section{FÁVERO E SUA TRAJETÓRIA INSTITUCIONAL}

Em 1913, Flamínio Fávero ingressou na Faculdade de Medicina de São Paulo, tendo concluído seu curso em 1919, fazendo parte da primeira turma que se graduou pela instituição. Após exercer o cargo de lente substituto das cadeiras de higiene e Medicina Legal, tornou-se professor catedrático de Medicina Legal em 1923. Fávero durante grande parte de sua carreira teve forte atuação na Faculdade, onde exerceu cargos de vice-diretor, secretário e diretor.

Também esteve à frente da Sociedade de Medicina Legal e Criminologia de São Paulo, que tinha como sede o Instituto Oscar Freire, desde sua criação em novembro de 1921, ocupando diversos cargos, de secretário a presidente, contribuindo de forma intensa na realização de pesquisas, congressos e publicações de trabalhos, abrangendo os mais diversos temas dentro da Medicina Legal ${ }^{8}$.

A Sociedade foi criada com o objetivo de aglutinar os profissionais envolvidos de alguma forma com a Medicina Legal e a Criminologia, principalmente médicos e juristas, enquadrandoos dentro da tradição anteriormente descrita da Escola Positiva e contribuindo para a formação de um campo de saber específico, voltado para a análise dos portadores de "desvios" e produção de conhecimento acerca destes, conhecimento este que deveria estar alicerçado sobre bases nacionais. Também fazia parte da agenda de trabalho de seus membros a conquista de um espaço de aplicação efetiva de tal conhecimento, que ia desde mudanças no quadro legislativo à criação de uma rede de instituições que se incumbissem tanto da regeneração dos indivíduos como da prevenção da prática do crime, atuando sobre seus corpos e mentes antes mesmo da manifestação do delito ${ }^{(3)}$.

No discurso proferido pelo jurista Alcantara Machado $^{9}$ na sessão de instalação da Sociedade, ele fez uma síntese bastante interessante acerca das idéias e objetivos que motivaram sua criação, falando:

Da revolução levada a effeito na segunda metade do seculo transacto por Cesar Lombroso, por seus discipulos e também por seus contradictores, um resultado ficou, victorioso e perduravel: a sciencia penal tornou-se uma sciencia positiva, nos methodos, que são os da observação e da experiencia, na materia, que são o criminoso e as condições do meio, e no objetivo que é a defesa social pela prevenção e pela repressão. Quaesquer que sejam as nossas convicções philosophicas, (...) é impossivel o regresso a concepção antiga do delicto, (...) e ao conceito anachronico da pena inspirada exclusivamente na natureza do crime, sem attenção à natureza do criminoso". Sendo assim, "a missão que nos impomos se resume em estudar a criminalidade em nosso ambiente physico e moral, os erros e as lacunas de nossas leis, a maneira de reprimir e prevenir o crime de acordo com as necessidades nossas, com nossa indole e com os nossos recursos ${ }^{9}$.

Para cumprir seu objetivo, a Sociedade de Medicina Legal e Criminologia de São Paulo vai se incumbir de promover uma série de congressos

(2) Sobre Lombroso e a recepção das ideias bio-deterministas no Brasil, veja Alvrez ${ }^{7}$ e Ferla ${ }^{8}$.

(3) Sobre a Sociedade de Medicina Legal e Criminologia de São Paulo, veja Ferla ${ }^{8}$. 
para a discussão de temas ligados à patologização do ato anti-social, tendo como alvos principais de seus estudos o criminoso, o menor abandonado, o homossexual e, a partir da década de 1940, a questão do trabalho. Com esses encontros, podiase dar maior visibilidade e circulação às idéias biodeterministas, bem como ampliar sua articulação com os órgãos envolvidos com a segurança pública. Políticas implementadas pelo poder público como, por exemplo, a obrigatoriedade da identificação dactiloscópica e a instalação de laboratórios de antropologia criminal em manicômios e penitenciárias, foram resultado desses encontros.

Outro instrumento de veiculação das ideias da Escola Positiva eram as revistas especializadas na área da Criminologia e da Medicina Legal. Durante principalmente os anos de 1920 a 1950, tem-se uma série delas, a maioria, segundo o próprio Fávero, de vida efêmera. A Sociedade publicava os Arquivos da Sociedade de Medicina Legal e Criminologia que, se comparada com suas congêneres, teve vida longa. A publicação constituía-se como um veículo privilegiado de publicação dos artigos escritos pelos profissionais da área, bem como incumbia-se do registro dos acontecimentos sociais da Sociedade, tais como, congressos, reuniões e comemorações.

Em quase todos os números pode-se encontrar textos de pesquisas realizadas por Fávero, a maioria delas, porém, relativas a aspectos mais técnicos da Medicina Legal, não tendo grande produção no estudo do delinquente, propriamente dito. De qualquer forma, a participação do médico na revista inclui a produção de vários discursos, de balanços das atividades da Instituição e de textos que discutiam o campo de atuação da disciplina, constituindo-se como um material de suma importância para o pesquisador que pretende aprofundar a análise a respeito da formação da Medicina Legal como espaço de saber e de atuação no meio social. Em um desses discursos, Fávero, por ocasião das comemorações dos 25 anos de fundação da Sociedade, fez um balanço de suas atividades, declarando que esta:

(...) muito fêz no campo que se propôs cultivar. Enriqueceu a bibliografia nacional com monografias e livros de valor; concorreu para a feitura e interpretação de leis de interêsse coletivo; colaborou na criação de instituições de necessidade publica; convocou e orientou certames culturais; distribuiu prêmios científicos para estimular a produção de obras de projeção especializada $(\ldots)^{10}$.
Como espaço de implementação dos ideais da Escola Positiva de forma mais afirmativa, tem-se igualmente a Penitenciária do Estado de São Paulo, que fora inaugurada em 1920 como instituição modelo para a recuperação e reinserção de criminosos. Em 1939, foi criado na Penitenciária, por meio do decreto n. 10.773, o Serviço de Biotipologia Criminal. Tinha por modelo o pioneiro Laboratório de Antropologia Criminal criado no Rio de Janeiro, em 1932, pelo médico Leonídio Ribeiro ${ }^{11}$. O Serviço de Biotipologia, além dos estudos do criminoso, era o responsável pela organização da Revista Penal e Penitenciária, de uma biblioteca especializada e de um museu. Essa iniciativa contou com o amplo apoio do Conselho Penitenciário e com a participação direta de Flamínio Fávero ${ }^{11}$. Em 1941, o Serviço se tornou Instituto de Biotipologia, que passava a ter uma estrutura mais ampliada compreendendo seções como a de antropometria, endocrinologia, psiquiatria, psicologia e sociologia para atender às demnadas da justiça, da administração e do Conselho Penitenciário ${ }^{12}$. Fávero, por ocasião da reformulação do Instituto e ampliação de suas atribuições, declarou:

\begin{abstract}
É o reconhecimento definitivo de que o auxílio da medicina se torna indispensável para a eficaz terapêutica dos criminosos e, ainda, de que ela e o Direito precisam viver lado a lado, em paz, de mãos dadas, sem ressentimentos e nem ciúmes, visando ao bem coletivo. Cada uma dessas ciências tem sua tarefa no agregado social e deve executá-la sem pretender invadir seara alheia (...). Nessas bases, a harmonia será completa e os resultados práticos da sinergia de ação, sem limites ${ }^{13}$.
\end{abstract}

O médico também teve destaque na área penal a partir de 1928, quando tornou-se membro do Conselho Penitenciário. Criado em março daquele ano, o Conselho constituía-se como um órgão informativo, responsável pelo estudo de processos de livramento condicional, comutação de pena e indulto. Os pareceres sobre os pedidos de livramento condicional e indulto eram elaborados a partir de documentos internos da Penitenciária, sobretudo do Instituto de Biotipologia Criminal. Segundo Fávero "as conclusões (...) são firmadas em elementos inúmeros e rigorosos que orientam e esclarecem o problema básico da possível readaptação do sentenciado ao meio livre"14.

A entrada de Fávero no Conselho Penitenciário inaugura uma participação mais efetiva do médico no estudo e implementação das 
Alvarez MC et al. Medicina legal, criminologia e punição: aspectos da trajetória intelectual e profissional.

políticas voltadas ao crime e à punição, refletindo-se em uma grande quantidade de artigos, publicados principalmente na "Revista Penal e Penitenciária" que esclarecem um pouco da militância do médico nessa área. Essa atuação se estenderá ao longo de sua carreira, tendo como ponto máximo os anos de 1942 a 1945. Nesse período, foi nomeado presidente do Conselho, e assume o cargo de Diretor da Penitenciária do Estado que acumulava as funções de Diretor Geral do Departamento de Presídios do Estado.

Idealizado por Acácio Nogueira, então secretário de segurança do Estado de São Paulo o órgão compreendia, segundo artigo publicado por ocasião de sua criação, as seguintes instituições: Penitenciária do Estado; Presídio Agrícola de Taubaté; Presídio Anchieta; Lar Juquiá, Casa de Detenção; Manicômio Judiciário; Presídio de Mulheres e Instituto de Biotipologia. Tendo como objetivo contribuir para o “(...) programa administrativo do governo do interventor Fernando Costa, que se orienta principalmente tendo em vista a justiça, a cultura e o aperfeiçoamento técnico dos serviços públicos do Estado"15.

Flamínio Fávero foi indicado para o cargo como substituto de Acácio Nogueira, que morreu uma semana antes da implementação do Departamento. Porém, apesar de ser escolhido em caráter de suplência, o discurso do secretário da Justiça, Abelardo Vergueira César, por ocasião da posse do médico, traz alguma dimensão do espaço que profissionais como Flamínio haviam conquistado no que dizia respeito à administração do sistema prisional da época:

(...) homens públicos devem manter a freqüência de seus entendimentos com os homens da ciência, para que os rumos da administração se norteiem no sentido das trajetórias que as conquistas científicas vão assinalando através dos tempos. (...) a escolha do novo Diretor dos Presídios obedece aquela norma. (...) o professor Fávero estava indicado para dar rumos a um departamento que longe de ser tão só uma repartição administrativa era, também, um conjunto complexo de institutos científicos. (...) É oportuno acentuar-se que se precisa prosseguir na sabia política de humanização do detento", encarando-o dentre de seus característicos reais e não só dentro dos característicos ideais. "(...) Tais rumos explicam e justificam as últimas inovações dos nossos presídios, que devem ser cada vez mais institutos de tratamento, de readaptação (...) e não simples casas de correção ${ }^{16}$.

As declarações de Fávero na solenidade de posse corroboram as expectativas do secretário:

(...) Não haverá, pois, qualquer desarmonia entre os planos traçados e sua efetivação. (...) À sociedade, mais do que o castigo dos que erram, interessa a sua restauração moral. O criminoso é em regra um desambientado. Mister se faz, pois, articula-lo no seu posto, para o trabalho construtivo. (...) Mas isso, pela bondade, pela caridade, pelo amor. Se os criminosos são nossos semelhantes, apenas, transviados, por que não dominá-los pelo jugo irresistível do nosso amor? ${ }^{16}$.

Durante os dois anos em que esteve à frente do sistema penitenciário paulista, sua atividade, segundo amigos e companheiros de profissão, esteve sempre voltada para o que eles chamaram de uma administração humanitária em relação aos presos. Os relatos feitos por ocasião de sua morte nos contam que o médico, além de ser adepto da laborterapia ${ }^{(4)}$, sempre ouvia os detentos individualmente tomando nota de sua situação, bem como de suas reclamações ${ }^{(5)}$. No período de sua gestão também fora criado um jornal onde eram publicados artigos de presos e funcionários da penitenciária.

Um artigo publicado ${ }^{17}$ durante sua gestão como diretor da Penitenciária e que trata dos problemas sexuais dentro da instituição, ou seja, do direito ou não do interno em ter visitas íntimas, traz alguns pontos referentes ao que seria o projeto administrativo de Fávero. Ele inicia sua reflexão posicionando-se contra as visitas íntimas, argumentando ser a continência sexual um aspecto importante da terapêutica de "regeneração" do criminoso. Segundo ele, sendo a recuperação a finalidade da pena, somente aqueles que estão aptos a adaptar-se ao tratamento, de forma consciente e voluntária, ou seja, aquelas que aceitam todos os termos do "contrato", podem permanecer em instituições voltadas para a regeneração.

A seleção dos indivíduos, considerados pelo médico como adequados ao tratamento, deveria ser feita pelo Instituto de Biotipologia Criminal, através do estudo das características do criminoso, selecionando os que estariam aptos a receber a educação, finalidade principal da pena. A

(4) Idéia da regeneração do criminoso por meio do trabalho que como foi discutido no texto é um dos pressupostos básicos da Escola Positiva.

(5) O resultado de tais entrevistas fora compilado pelo médico em uma obra denominada "Incursões pela criminologia", e caso tenha sido publicada, ainda não foi possível localiza-la. 
permanência daqueles que não se enquadram na terapêutica, que são segundo Fávero, os psicopatas ou quase, é extremamente prejudicial tanto para a instituição prisional quanto para o próprio detento ${ }^{17}$.

Fávero complementa seu artigo falando dos aspectos que, segundo ele, deveriam estar presentes em um ambiente propício à regeneração: "(...) trabalho adequado, exercícios físicos, educação intelectual, artística, moral, religiosa e sexual, regime celular noturno, regime social diurno, higiene rigorosa, alimentação convincente, exames médicos periódicos e proscrição de visitas femininas de puro turismo (...)"17.

Em um discurso ${ }^{18}$ proferido pelo médico por ocasião da inauguração do Presídio de Mulheres da Penitenciária de São Paulo, que funcionou no prédio que antes servia de residência aos diretores da Penitenciária e foi administrado pela Irmandade do Bom Pastor, Fávero trata das especificidades do tratamento aplicado à mulher para sua regeneração. Este diferencia-se do masculino, principalmente, pelo fato de ser o lar o ambiente principal da mulher e por isso, sua reconstituição moral deve prepará-la para o retorno a este, procedendo-se a reeducação através de trabalhos domésticos, fazendo com que elas vejam o cárcere como sendo um lar comum( ${ }^{(6)}$.

O afastamento de Fávero da direção do Departamento de Presídios foi motivado pela ocorrência de uma rebelião na penitenciária em fins de março de 1945. Foram encontradas poucas informações referentes ao acontecimento, não sendo por isso, possível apresentar informações detalhadas sobre o motim. A imprensa do período noticiou apenas que:

O respeito que os sentenciados tributam ao prof. Flamínio Fávero evitou piores consequências. (...) Avisado da ocorrência, o prof. Flamínio Fávero encaminhou-se para o $2^{\circ}$ pavimento dirigindo-se aos amotinados, que se entregaram pacificamente. Assim, o respeito que os sentenciados tributam ao diretor da Penitenciária evitou que o motim tivesse trágicas consequencias. O prof. Flamínio Fávero aproximou-se então dos três sentenciados e os levou até as suas celas ${ }^{20}$.

Apesar do sucesso na contenção da rebelião, atribuído a Fávero tanto pela imprensa quanto por alguns de seus companheiros que escreveram sobre o incidente, o médico decidiuse por abandonar o cargo logo após a ocorrência do motim, não ficando claros os motivos que o levaram a tal decisão. Em um artigo escrito por
Antônio Constantino e publicado pelos Arquivos da Sociedade ${ }^{21}$, o autor aponta como causa para seu afastamento o fato de Fávero não ser católico. Apontando o argumento como sendo insuficiente para que tão competente administrador deixasse seu posto, o autor declarava que: "católico ou não, êle formou a consciência do cristão puro, sincero, haurindo nas letras das sagradas Escrituras a lição eterna da piedade do Cristo. Protestante que é, a sua vida tem sido exemplo de virtudes e do bemfazer, aliado à sabedoria que lhe dá projeção nos tempos modernos (...)"21. É certo que Flamínio Fávero foi o primeiro diretor da Penitenciária que frente à recusa de alguns presos em receber a orientação religiosa católica, facultou aos detentos a possibilidade de realização de outros cultos, em particular o protestante ${ }^{22}$

Mesmo não conseguindo recuperar elementos que mostrem o real motivo do afastamento de Fávero, sua atuação foi marcada por inúmeros elogios por parte de seus colegas de profissão, como era costume, já que esses estavam empenhados em marcar não só os seus nomes, mas também o de seus companheiros, em uma tradição que passava pela atuação efetiva desses profissionais no que tange aos estudos de Medicina Legal e Criminologia e as atividades ligadas ao sistema prisional, entre outros aspectos. É interessante notar que essa tradição conseguiu repercussão de alguma forma mesmo na esfera política, como mostram as declarações feitas na plenária pelo deputado estadual Camillo Ashar a respeito da atuação de Fávero frente à Penitenciária e que fazem parte do mesmo excerto com o qual inicia-se esta reflexão. Segundo ele:

Como penitencialista, orientado pelos novos progressos da ciência e pelos princípios do Cristianismo, marcou excelente atuação na mais alta direção de nossa Penitenciária, substituindo a violência pela simpatia, o castigo pelo conselho, a segregação pelo convívio controlado, os poucos recomendáveis processos administrativos pela mais reta gestão. Dela se afastou, já cansado, mas não desiludido de seu método; afastou-se apenas para não mais permanecer junto, nem se chocar com aquêles a quem a sua bondade e perfeição de caráter representavam brasas vivas que, dia a dia, se amontoavam sobre as próprias cabeças...1.

Por fim, cabe mencionar a participação de Flamínio, nos anos 1930, num grupo formado por juristas, como Roberto Lyra, que foi encarregado de elaborar um anteprojeto para o Código Penitenciário do Brasil 22 .

(6) Sobre a criação do presídio de mulheres em São Paulo, veja Angotti ${ }^{19}$. 


\section{CONSIDERAÇÕES FINAIS}

O esboço, aqui apresentado, de análise da trajetória de Flamínio Fávero abre interessantes perspectivas de investigação no campo da história da Medicina Legal, das ideias criminológicas e das instituições de controle social no país. Por um lado, Fávero provavelmente apresentava um perfil mais "técnico" em termos de atuação intelectual no campo da Medicina Legal, já distante dos considerados fundadores desse saber no Brasil como Nina Rodrigues, Afrânio Peixoto e outros mas, ao mesmo tempo, não rompia explicitamente com essa tradição. Dominichi $\mathrm{Sá}^{23}$ afirma que a investigação histórica mais recente acerca das atividades científicas no Brasil tem indicado que as rupturas nas formas de produção intelectual no país não foram necessariamente abruptas, mesmo com a emergência de perfis mais especializados nas mais diversas áreas de conhecimento, sobretudo a partir do início do século XX. De muitas formas, mesmo os especialistas atuaram como intérpretes da cultura, da sociedade e da política e igualmente como reformadores sociais. Os aspectos aqui levantados da trajetória de Fávero apontam na mesma direção. Sua atuação em instituições no âmbito do sistema penitenciário da época indica, por sua vez, como os médicos haviam conquistado um campo de atuação efetivamente mais amplo nos assuntos referentes à punição, inclusive com alguma repercussão política, campo que, em grande medida, será reduzido nas décadas seguintes.

Além do interesse puramente cognitivo, a investigação sociológica e histórica, aqui apenas esboçada, permite desnaturalizar as ideias acerca do crime e da punição, bem como o papel dos diferentes saberes que buscam descrever e compreender tais fenômenos sociais. Num momento em que não apenas os conhecimentos técnicos no âmbito forense estão em acelerada transformação, mas que também as concepções sociais acerca do crime e da punição estão em mutação e emergem novas políticas de combate ao crime, reconstruir experiências passadas pode contribuir para colocar em perspectiva os debates atuais e problematizar as evidências e pressupostos do presente.

Alvarez MC, Salla F, Alves KL. Forensic medicine, criminology and punishment: some aspects of intellectual and professional trajectory of Flamínio Fávero (1895-1982). Saúde, Ética \& Justiça. 2012;17(2):57-65.

ABSTRACT: the article discusses some aspects of intellectual and professional trajectory of Flamínio Fávero (1895-1982). Fávero studied at the Faculty of Medicine of São Paulo, Brazil and he played an important role in the field of forensic medicine and criminology at time, as well he served on the state prison system. This kind of research opens others possibilities for understanding the role of elites and their representations about the crime control and the practices and institutions of punishment in history of Brazilian society.

KEYWORDS: Forensic medicine/history; Criminology/history; Physicians/history; Coroners and medical examiners/history; Crime; Punishment.

\section{REFERÊNCIAS}

1. Ashcar C. Flamínio Fávero: um homem de bem. São Paulo: [s.n.]; 1950.

2. Alvarez MC, Salla F, Souza LA. A sociedade e a lei: o Código Penal de 1890 e as novas tendências penais na Primeira República. Justiça História, Porto Alegre. 2003;3(6):97-130.

3. Alvarez MC, Salla F, Souza, LA. Políticas de segurança pública em São Paulo: uma perspectiva histórica. Justiça História, Porto Alegre. 2004;4(8):173-99.

4. Antunes JLF. Medicina leis e moral: pensamento médico e comportamento no Brasil (1870-1930). São Paulo: Edunesp; 1998.

5. Fávero F. Evolução Scientifica da Medicina Legal no Brasil. Arch Soc Med Legal Criminol São Paulo.
1922;।(3):141-3.

6. Corrêa M. As ilusões da liberdade: a escola Nina Rodrigues e a antropologia no Brasil. Bragança Paulista: EdUSF; 1998. p.132.

7. Alvarez M. Bacharéis, criminologistas e juristas: saber jurídico e nova escola penal no Brasil. São Paulo: IBCCrim; 2003.

8. Ferla LA. Feios, sujos e malvados sob medida: do crime ao trabalho, a utopia médica do biodeterminismo em São Paulo (1920-1945) [tese]. São Paulo: Faculdade de Filosofia, Letras e Ciências Humanas, Universidade de São Paulo; 2005.

9. Machado A. Discurso proferido na sessão de instalação pelo Dr. Alcantara Machado. Arch Soc Med Legal Criminol São Paulo. 1922;I(1):13-6. 
Alvarez MC et al. Medicina Legal, Criminologia e Punição: aspectos da trajetória intelectual e profissional.

10. Fávero F. Discurso de abertura da sessão solene de 15 de novembro de 1946. Arq Soc Med Legal Criminol São Paulo. 1946;17(1-3):84.

11. Duas grandes realizações na Penienciária de São Paulo. Rev Penal Penitenciária. 1940;1(1):236.

12. Do Instituto de Biotipologia Criminal. Rev Penal Penitenciária. 1941;2(1,2):446.

13. Fávero F. Revista Penal e Penitenciária. v.4-8.

14. Fávero F. Conselho Penitenciário do Estado. Folha Manhã, São Paulo, 28 mar. 1948.

15. Departamento de Presídios do Estado. O Estado de São Paulo, 08 abr. 1943. p.6.

16. Departamento de Presídios do Estado - posse de seu diretor geral, professor Flamínio Fávero. O Estado de São Paulo, 10 abr. 1943. p.5.

17. Fávero F. O problema sexual nas prisões. Rev Penal
Penitenciária. 1947;VIII(1,2):113-128.

18. Fávero F. Discurso por ocasião da inauguração do Presídio de Mulheres da Penitenciária de São Paulo. Rev Penal Penitenciária. 1942;3(1,2):325-7.

19. Angotti B. Entre as leis da ciência, do Estado e de Deus. São Paulo: IBCCRIM; 2012.

20. Três sentenciados provocam desordens e agrediram cinco pessoas. O Correio Paulistano, mar 03; 08 1945.

21. Constantino A. Flamínio Fávero e a penitenciária. Arq Soc Med Legal Criminol São Paulo. 1945;16(13):25.

22. Brito L. Evolução do sistema penitenciário brasileiro. Rev Penal Penitenciária. 1942;3(1,2):91-2.

23. Sá DM. A ciência como profissão: médico, bacharéis e cientistas no Brasil (1895-1935). Rio de Janeiro: Fiocruz; 2006. 